\title{
Olympic Games in China-a catalyst for smoke-free environments
}

\section{Lin Yan}

The 2008 Beijing Olympic Games are not only an international celebration of the performances of supreme athletes, but an opportunity to deliver a lasting Olympic legacy of smoke-free environments to the majority of China's population of 1.3 billion people.

Until recently, China's 350 million smokers have been able to smoke anywhere, at any time and with little awareness of the dangers of smoking to themselves, the people they work with or their families. All that is changing since the Chinese government ratified the Framework Convention for Tobacco Control in 2005 and made a public commitment to continue the tradition of tobacco-free Olympic Games that began in Calgary 20 years ago.

This year alone has seen the implementation of a smoke-free regulation in Beijing for

Correspondence to: Professor Lin Yan, China Resource Center of the International Union Against Tuberculosis and Lung Disease; ylin@iuatld.org its population of 15 million people requiring most public places, including sports venues, offices and hospitals to be $100 \%$ smoke-free from 1 May. As has happened in most other international jurisdictions, the bans in restaurants are partial as part of a two-step plan towards achieving 100\% smoke-free environments in 2009.

The Olympic venues are tobacco-free and smoke-free policies are reinforced by mass media messages, developed with assistance from the World Lung Foundation, that for the first time warn of the dangers of smoking and secondhand smoke.

With continuing support from government leaders who now no longer smoke in public and the Bloomberg Initiative (BI), the momentum continues to grow, with all other Olympic cities in mainland China working on smoke-free regulations and building capacity for tobacco control. Shenyang, with its population of nine million has also implemented a smokefree regulation from 14 May with four other cities expected to follow this year.
As major events are a proven catalyst for smoke-free initiatives, Guangzhou and Shanghai are now using the Asian Games and World Expo, respectively, in 2010 to develop smoke-free city plans to improve the health of their combined population of 28 million.

The students enjoying eating in a smoke-free restaurant in Beijing (see cover) are public health students at Peking University-one of seven universities that have a BI funded project to jointly develop a tobacco control curriculum and tobacco-free campus policywith the potential to expand this model to the other 61 public health faculties in universities throughout China.

With one million deaths a year from smoking the challenges may be daunting, but they are not insurmountable if we wisely use the evidence, resources and opportunities to implement effective tobacco control strategies.

More people will suffer and die in China from smoking than in any other country-but decisive action by government leaders, BI partners and other key agencies can together reverse the tobacco epidemic in a magnificent country where a third of the world's smokers work and live.

\section{Competing interests: None.}

Tobacco Control 2008:17:217. doi:10.1136/tc.2008.026526 